\title{
Human testicular peritubular cells: more than meets the eye
}

\author{
Artur Mayerhofer \\ Anatomy III - Cell Biology, Ludwig Maximilian University (LMU) Munich, Biedersteiner Strasse 29, \\ D-80802 Munich, Germany \\ Correspondence should be addressed to A Mayerhofer; Email: mayerhofer@Irz.uni-muenchen.de
}

\begin{abstract}
In healthy men, several layers of inconspicuously flat cells and extracellular matrix (ECM) proteins build the wall of the seminiferous tubules. The cells of this wall, peritubular cells, are not well characterized. They are smooth-muscle-like and contractile and transport immotile sperm, a function important for male fertility. However, their full functional importance, especially their potential contribution to the paracrine regulation of the male gonad, is unknown. In men with impaired spermatogenesis, the architecture of the tubular wall is frequently altered. Deposits of ECM and morphological changes of peritubular cells imply that functions of peritubular cells may be fundamentally altered. To be able to study human peritubular cells and their functions, a culture method was established. It is based on small biopsies of patients with obstructive azoospermia but normal spermatogenesis (human testicular peritubular cells, HTPCs) and non-obstructive azoospermia, impaired spermatogenesis, and testicular fibrosis (HTPCFs). Results obtained from cellular studies and parallel examinations of biopsies provide insights into the repertoire of the secretion products, contractile properties, and plasticity of human peritubular cells. They produce ECM components, including the proteoglycan decorin, which may influence paracrine signaling between testicular cells. They may contribute to the spermatogonial stem cell niche via secreted factors. They are regulated by mast cell and macrophage products, and in response produce factors that can fuel inflammatory changes. They possess a high degree of plasticity, which results in hypertrophy and loss of contractile abilities. The data collectively indicate important roles of inconspicuous testicular peritubular cells in human male fertility and infertility.

Reproduction (2013) 145 R107-R116
\end{abstract}

\section{Peritubular cells of the testis: of mice and men}

The wall of the seminiferous tubules in the adult human testis is a rather small compartment within the adult male gonad, which has not received much attention (Maekawa et al. 1996). Striking species differences are obvious. In man, several layers of elongated, very thin, spindle-shaped, peritubular cells and extracellular matrix (ECM) proteins form this compartment. This is in contrast with the single cell layer and negligible ECM, which form the tubular wall in laboratory rodents. In either case, peritubular cells in the adult express markers for smooth-muscle-like cells, e.g. smooth muscle actin (Anthony \& Skinner 1989, Tung \& Fritz 1990, Albrecht et al. 2005). Differences in the cellular phenotypes between the inner and outer layers in man were suggested, according to results of immunohistochemical studies. The inner layers stained with desmin, supporting their smooth muscle phenotype, while the outer ones stained mainly with vimentin, implying a connective tissue phenotype (Davidoff et al. 1990). The smooth muscle characteristic, i.e. expression of smooth muscle actin, appears to be induced around puberty in primates mainly by androgens, which appear to play a crucial role in the differentiation of peritubular cells. FSH has an additive role, implying that both Leydig cells and Sertoli cells may govern differentiation of peritubular cells. Once induced, smooth muscle actin expression appears to remain unchanged, even if the hormonal stimulation is removed (Schlatt et al. 1993).

The effects of androgens on peritubular cells may go beyond the induction of the structural contractility protein smooth muscle actin. This can be concluded from recent studies, in which the androgen receptor of murine peritubular cells was selectively knocked out (Welsh et al. 2009). As a consequence, the mice were azoospermic and infertile. Thus, peritubular cells are probably essential for the development of overall testicular function, spermatogenesis, and fertility, at least in rodents (see also Nurmio et al. (2012)).

How peritubular cells are involved in the orchestration of testicular functions in the adult remains to be fully shown. The anatomical 'strategic' position of peritubular cells within the testis, namely at the interface of the interstitial, i.e. Leydig cell compartment, and the Sertoli cell/germ cell, i.e. tubular compartment, intuitively suggests multiple paracrine roles of these cells within 
the testis. Indeed, several studies revealed important paracrine influences exerted by peritubular cells on somatic cells. In mice, in which the peritubular cell androgen receptor was knocked out, Leydig cell markers (e.g. steroidogenic factor 1, IGF and IGF3) were significantly reduced in a certain population of Leydig cells (Welsh et al. 2012). Thus, Leydig cells are among the somatic cells that are under the control of factors derived from peritubular cells.

That Sertoli cell function was also impaired in the knockout mice mentioned does not come as a surprise. Earlier reports postulated paracrine interactions and the factor involved was termed 'peritubular factor that modulates Sertoli cell function' (Skinner \& Fritz 1985). This probably represents a cocktail of different factors, which have not been further characterized (Verhoeven et al. 2000).

Sertoli cells are of crucial importance for all male germ cells and are thought to provide the structural and functional environment for the spermatogonial stem cell (SSC). An influence of peritubular cells on Sertoli cells may therefore have consequences also for the SSC. Peritubular cells and SSC are separated only by a basal lamina and hence peritubular cells may also directly contribute to the SSC niche, e.g. via secreted factors (Oatley \& Brinster 2012).

An important and accepted role of peritubular cells is the active transport of immotile sperm (Hargrove et al. 1977). A few years ago, it was even speculated that interference with the contractile abilities of seminiferous tubules, i.e. cycles of contraction, and relaxation of peritubular cells, may be a strategy for human male contraception (Romano et al. 2005). In previous mouse studies (Zhang et al. 2006, Welsh et al. 2009), the lack of androgen receptors in peritubular cells most probably prevented the functional maturation of these cells, which normally occurs at puberty. It therefore appears possible that the consequent lack of contractility of seminiferous tubules may also have contributed to the observed infertility. Unfortunately, this was not tested.

Factors involved in the regulation of contraction and relaxation of peritubular cells appear numerous. They were studied both in rodent isolated peritubular cells and in human isolated whole seminiferous tubules. Local factors, e.g. endothelin 1 (Romano et al. 2007, Losinno et al. 2012), platelet-derived growth factor (PDGF; Romano et al. 2006), prostaglandins, and neurotransmitters (Miyake et al. 1986, Tripiciano et al. 1998), may play a role, as do hormones, including sex steroids (Yamamoto et al. 1989) and the pituitary hormone vasopressin. In rat peritubular cells, receptors for vasopressin (V1a), in contrast to endothelin receptors, appear to be under developmental control. They are present in the adult rat, but absent before puberty (Howl et al. 1995).

In this context, it is important to bring to mind that the tubular wall compartment in subfertile or infertile men with impaired spermatogenesis is typically remodeled. It is textbook knowledge that testicular tubular fibrosis, best evidenced by deposits of ECM, is considered a hallmark of male infertility. Fibrosis and morphological changes of peritubular cells, including hypertrophy, reported by several studies (Haider et al. 1999, Schell et al. 2010, Welter et al. 2013), may imply that specific functions of peritubular cells, possibly including paracrine and contractile abilities, are altered (Figs 1 and 2). If so, the following questions arise: what is/are the reason(s) for the changes, what may initiate and drive the changes, and do they indeed affect testicular function?

The reasons for the changes may be related to intrinsic plastic properties of smooth muscle cells. Typical smooth muscle cells, e.g. from the vasculature, are well known for their ability to undergo dramatic phenotypic changes due to a plethora of influences, including inflammatory factors (Alexander \& Owens 2012, Welter et al. 2013). As testicular peritubular cells share characteristics of smooth muscle cells, the changes in the tubular wall occurring in the testis of infertile men could simply indicate phenotype switches. In support of this, adult rodent peritubular cells in culture were reported to undergo striking changes, e.g. in response to endothelin and PDGF, which cause hypertrophy (Romano et al. 2006, 2007). Thus, testicular peritubular cells are able to respond to stimulation by a phenotypic adaptation.

What may trigger the phenotype changes in the human testis? Recently, another alteration in the wall of human seminiferous tubules in infertility patients became clear, namely the presence of abundant immune cells, i.e. macrophages and mast cells (Fig. 1; Hashimoto et al. 1988, Nagai et al. 1992, Apa et al. 2002, Hussein et al. 2005, Roaiah et al. 2007). Thus, mast cell-specific genes are strikingly and robustly increased in testes samples from infertile men (Spiess et al. 2007). Immunohistochemistry combined with morphometric studies and electron microscopy revealed that activated mast cells specifically accumulate in the wall of those seminiferous tubules, which display impaired spermatogenesis (Meineke et al. 2000, Frungieri et al. 2002a, Welter et al. 2011). Tryptase is a prototype mast cell marker and the number of tryptase-immunoreactive mast cells was positively correlated with the thickness (i.e. the extend of fibrosis) of the walls of seminiferous tubules (Meineke et al. 2000). In addition, increased numbers of CD68-positive macrophages were found (Frungieri et al. $2002 b$ ). Hence, the cellular and extracellular composition (i.e. fibrosis) and consequently the local microenvironment of afflicted tubular walls are altered in states of human male infertility. Although not examined, interactions between immune cells and peritubular cells could result in a phenotype switch of peritubular cells, in fibrosis of the tubular wall (Levi-Schaffer \& Piliponsky 2003, Duchesne et al. 2011) and other unexplored changes. 

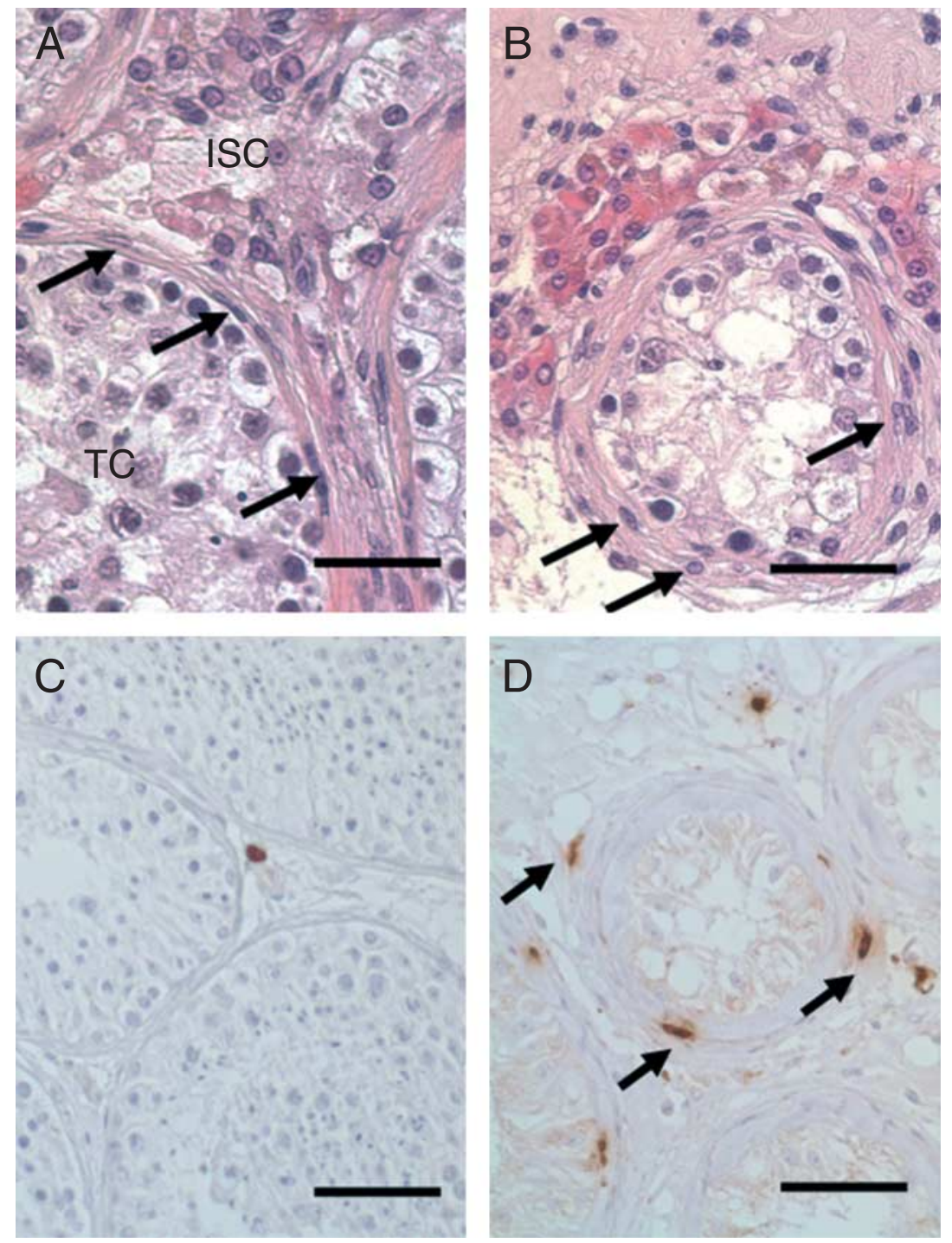

Figure 1 Testicular morphology and composition of the tubular wall in the adult human testis in health (normal spermatogenesis; A and C) and disease (infertility B and D). (A) The tubular wall (arrows) is normally an inconspicuous compartment, in which only few nuclei of peritubular cells are visible in hematoxylin and eosin (H\&E)-stained sections. Note the close proximity of the tubular wall to the tubular compartment (TC) containing Sertoli cells and germ cells and to the interstitial compartment (ISC) with Leydig cells. Bar: $30 \mu \mathrm{m}$. (B) In samples from infertility patients, the tubular wall is often enlarged, deposits of ECM are seen, and both elongated and round peritubular cell nuclei (arrows) are seen in the thickened wall. H\&E stain. Bar $\sim 30 \mu \mathrm{m}$. (C and D) Immunohistochemical identification of mast cells containing tryptase, in a normal testis $(\mathrm{C})$ and in a testicular biopsy of an infertility patient (D). Note that in the section of the normal testis, only one mast cell is present in the interstitial compartment (C). In contrast, in the section from the infertility patient, several mast cells are seen and accumulate in the wall of seminiferous tubules (arrows in D). Bar $\sim 60 \mu \mathrm{m}$.
All these changes may be of importance for spermatogenesis and human male fertility. But how can human peritubular cells and the tubular wall be studied? As mentioned, the rodent tubular wall has a simple architecture, lacks appreciable ECM and immune cells. Hence, peritubular cells in rodents may differ functionally from human peritubular cells. This point can, however, not be fully judged, because despite several studies on rodent peritubular cells, only very few papers dealing with human testicular peritubular cells (HTPCs) have appeared. As a further caveat, these few studies examined samples from boys with cryptorchidism or androgen insensitivity syndrome (Chemes et al. 1985, 1992, Cigorraga et al. 1994) and therefore would not reflect the situation of the adult human testis. A recent case report indicates that peritubular cells of the human testis may be able to form tumors (Du et al. 2012). This benign testicular tumor type is very rare and only six additional cases have been reported (see Du et al. (2012)). While peritubular tumor cells might turn out to be an interesting experimental tool in the future, they are, to my knowledge, not yet available for cellular studies.

Hence, to be able to explore HTPCs in health and disease, i.e. infertility, one has to develop adequate human cellular models. In an attempt to do so, our laboratory established a method to culture and study HTPCs. It is based on very small testicular tissue samples from adult patients with obstructive azoospermia but normal spermatogenesis (HTPCs) and non-obstructive azoospermia, impaired spermatogenesis, and testicular fibrosis (HTPCFs) (Albrecht et al. 2006, Schell et al. 2008, 2010, Spinnler et al. 2010, Adam et al. 2011, 2012).

Insights obtained from any cellular model must be viewed with caution in general, and our data in particular, because similar studies on human peritubular cells coming from other laboratories are, to my 

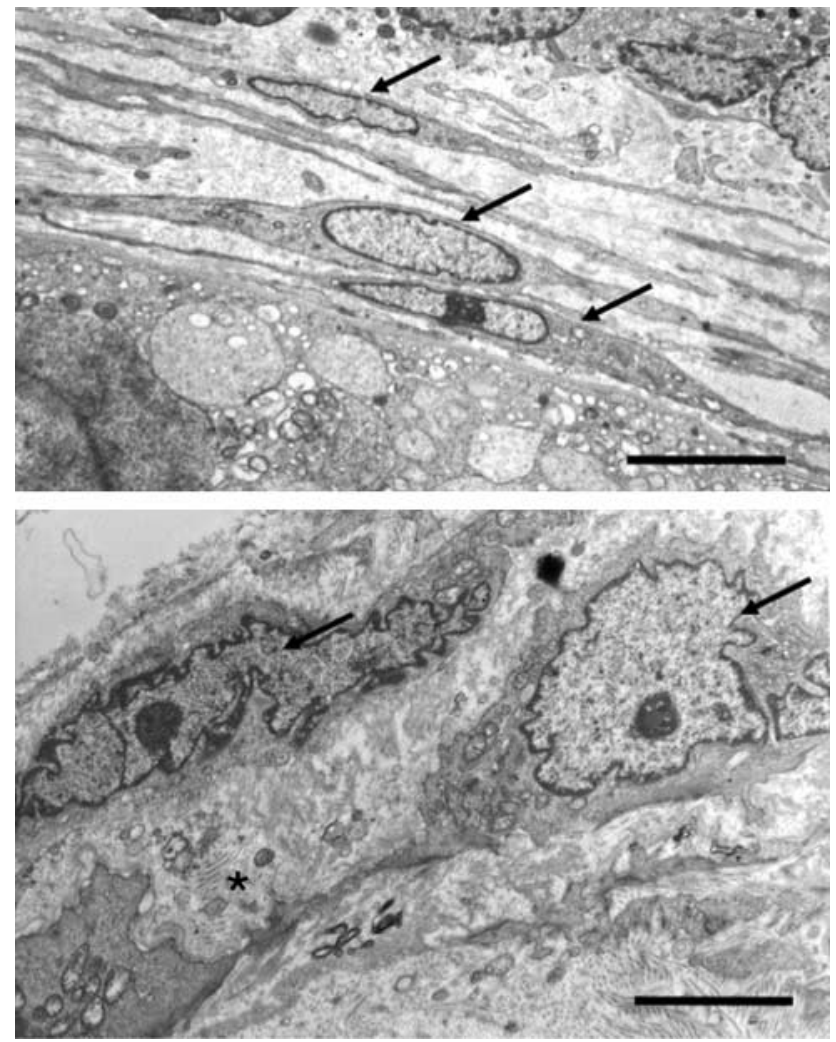

Figure 2 Electron microscopy of human peritubular cells in the wall of seminiferous tubules. (Top) In the healthy adult, several layers of thin, peritubular cells (arrows at nuclei) and ECM form the wall of seminiferous tubules. Bar: $\sim 3 \mu \mathrm{m}$. (Bottom) The morphology of the tubular wall of an infertility patient reveals cellular hypertrophy (arrow at nucleus) and increased ECM (asterisk). Bar: $\sim 4 \mu \mathrm{m}$. These micrographs are taken with permission from Fig. 2 of our previous paper (Schell et al. 2010). Copyright 2010, reproduced with permission from The Endocrine Society.

knowledge, not yet available. Are HTPCs and HTPCFs indeed good models? First of all, one must bear in mind that HTPCs, derived from men with obstruction of the vas deferens, despite normal spermatogenesis and testicular morphology, may not necessarily be completely normal cells. Yet other samples are not available. Secondly, various underlying and often unknown causes for infertility in case of HTPCFs may complicate the interpretation of the results. Thirdly, due to the explant culture approach, the cells examined may represent only a very viable subpopulation of the cells, which build the tubular wall.

Bearing all this in mind, we have complemented all cellular studies by parallel examinations of human biopsy samples using immunohistochemistry and/or laser microdissection, followed by RT-PCR analyses. Thus, by monitoring the in vivo situation, we can hopefully detect mere cellular phenomena. When done in combination, we strongly feel that the study of the cellular models provides a valuable experimental avenue to a better understanding of adult human peritubular cells. In this short review, key results are summarized. The focus is on unknown characteristics of peritubular cells and the role of immune cells.

\section{Recent insights into the nature of human peritubular cells}

\section{The basic phenotype of HTPCs}

The basic make-up of HTPCs was summarized previously (Albrecht et al. 2006, Albrecht 2009) and together with new insights shall be described. A short summary is provided in Table 1. Gene expression studies, confirmed by other methods, including western blotting, immunohistochemistry with biopsies, immunocytochemistry, RT-PCR, and ELISA techniques, revealed aspects of the basic make-up of HTPCs and HTPCFs. Their cellular phenotype is characterized by smooth muscle proteins, including smooth muscle actin, myosin heavy chain 11 (MYH11), calponin, cGMP kinase I (cgKI), and other smooth muscle markers (Schell et al. 2010, Welter et al. 2013). Examples of ECM proteins produced by HTPCs are several types of collagens, fibronectin, laminin, and secreted protein acidic and rich in cysteine (SPARC (osteonectin)) but also include the proteoglycan decorin (Albrecht et al. 2006, Adam et al. 2011, 2012). They produce signaling factors, including interleukin 6 (IL6), monocyte chemotactic protein 1 (MCP1), nerve growth factor (NGF), and its precursor proNGF, as well as glial cell line-derived neurotropic factor (GDNF). Cyclooxygenase-2 (COX2) was detected upon TNF $\alpha$ treatment and prostaglandins, especially PGD2, and metabolites may also be among the produced factors (Schell et al. 2008, Spinnler et al. 2010). The cells express several antioxidant proteins, namely catalase, parkinin/DJ-1, peroxiredoxin 1, superoxide dismutases (SOD) 1 and 2, glutathione-S-transferase, and heme oxygenase (HMOX1) (Kampfer et al. 2012). Finally, they possess receptors (R) for growth factors (GFs) including platelet-derived GFR and epidermal GFR (EGFR; see below), receptors for histamine (H1), TNF $\alpha$ (TNFR1/2), and tryptase (PAR2) (Albrecht et al. 2006, Schell et al. 2008, Adam et al. 2011, 2012). They also express androgen receptors (unpublished data) and peroxisome proliferator-activated receptor- $\gamma$ (Schell et al. 2010) and the intercellular adhesion molecule, ICAM-1.

Interestingly, to date, only two known and distinct differences between HTPCs and HTPCFs have become detectable, namely that HTPCFs produce significantly more decorin and catalase compared with HTPCs. This most probably reflects an altered in vivo situation, which persists in vivo and provides a unique, albeit small window into the human testis in health and disease, i.e. infertility (Adam et al. 2011, Kampfer et al. 2012). We anticipate that upon completion of ongoing proteomic studies, we will have information about the 
Table 1 Secreted products, cellular components, and receptors of human testicular peritubular cells.

\begin{tabular}{|c|c|c|}
\hline Name & Description & Regulation \\
\hline SMA & Structural protein & $15 \mathrm{dPG} 2 / \mathrm{ROS}$ \\
\hline MYH11 & Structural smooth muscle-specific protein, contraction & 15dPGJ2/ROS \\
\hline Calponin & Structural smooth muscle-specific protein, contraction & 15dPGJ2/ROS \\
\hline cGKI & Kinase involved in smooth muscle relaxation & $?$ \\
\hline $\mathrm{DCN}$ & $\begin{array}{l}\text { Secreted product, interacts with collagens, binds growth } \\
\text { factors (e.g. PDGF), ligand for growth factor receptors } \\
\text { (e.g. EGFR) }\end{array}$ & Increased by tryptase, TNF $\alpha$ (only in HTPCFs) \\
\hline MCP1 & Secreted chemoattractant factor for monocytes & Increased by TNF $\alpha$ \\
\hline IL6 & Secreted inflammatory cytokine & Increased by TNF $\alpha$ \\
\hline NGF/proNGF & $\begin{array}{l}\text { Secreted factor with roles in innervation, mast cell survival, } \\
\text { meiosis }\end{array}$ & Increased by TNF $\alpha$; proNGF/NGF affected by tryptase \\
\hline GDNF & Secreted factor important for spermatogonial stem cells & Constitutive release \\
\hline Catalase & Antioxidant action & ROS? \\
\hline Peroxiredoxin 1 & Antioxidant action & $?$ \\
\hline SOD $1 / 2$ & Antioxidant action & ? \\
\hline Park7/DJ-1 & Antioxidant action & $?$ \\
\hline EGFR (family) & Receptor family & $\begin{array}{l}\text { Proliferation, intracellular } \mathrm{Ca}^{2+} \text {; signaling inhibited } \\
\text { by DCN }\end{array}$ \\
\hline PDGFR $\alpha / \beta$ (family) & Receptor family & $\begin{array}{l}\text { Proliferation, intracellular } \mathrm{Ca}^{2+} ; \mathrm{DCN} \text { blocks } \\
\text { signaling by binding of ligand }\end{array}$ \\
\hline PAR2 & Receptor & $\begin{array}{l}\text { Increases intracellular } \mathrm{Ca}^{2+} \text {; activation by mast cell } \\
\text { tryptase }\end{array}$ \\
\hline $\mathrm{H} 1$ & Receptor & Increases intracellular $\mathrm{Ca}^{2+}$ \\
\hline TNFR1/2 & Receptor & MAPK, regulates MCP1, IL6 \\
\hline PPAR $\gamma$ & Receptor & Unknown \\
\hline AR & Receptor & Unknown \\
\hline
\end{tabular}

AR, androgen receptor; $\mathrm{CGKI}, \mathrm{CGMP-dependent} \mathrm{protein} \mathrm{kinase} \mathrm{1;} \mathrm{DCN,} \mathrm{decorin;} \mathrm{EGFR,} \mathrm{epidermal} \mathrm{growth} \mathrm{factor} \mathrm{receptor;} \mathrm{GDNF,} \mathrm{glial-cell-line-}$ derived neurotrophic factor; IL6, interleukin 6; MCP1, macrophage chemoattractant protein-1; MYH11, myosin heavy chain 11; Park/DJ1, parkinin/DJ-1; PAR2, protease-activated receptor 2; PDGFR, platelet-derived growth factor receptor; PPAR $\gamma$, peroxisome proliferator-activated receptor-gamma; Pro/NGF, pro/nerve growth factor; SMA, smooth muscle actin; SOD1/2, superoxide dismutases 1/2; TNFR1/2, tumor necrosis factor receptor $1 / 2$.

complete protein repertoire of these cells and their secretome.

It is of importance to note that the phenotypic features of peritubular cells (e.g. smooth muscle proteins) and the secreted products (e.g. NGF) are not to be regarded as fixed. As will be dealt with in the following sections, peritubular cells respond to immune cell derived factors, resulting in striking changes in their phenotype and their secreted factors (Fig. 3).

\section{HTPCs secrete the proteoglycan decorin, which acts as a paracrine factor and immune cell-derived factors stimulate decorin production}

Decorin was described in the human testis and specifically in the tubular wall years ago (Ungefroren et al. 1995). This proteoglycan interacts with collagens, 'decorates' collagen fibrils, and thus has defined structural roles in the ECM. Decorin is often increased in human organ fibrosis. In line with this, we also found stronger and more widespread expression in testes of infertility patients, which also showed testicular tubular fibrosis (Adam et al. 2011, 2012). Decorin has, however, important additional functions, including regulation of inflammation (Merline et al. 2011). Furthermore, decorin is an ECM factor, which is involved in storing GFs, and due to this ability, it can lower the levels of bioactive factors in tissues. In addition, it can directly bind to certain GF receptors. This is well known for the EGFR, which is expressed by peritubular cells and other cells in the human testis. In recent studies, we explored whether decorin may exert such actions also in HTPCs (Adam et al. 2011, 2012). Exogenous human recombinant decorin increased, like EGF, intracellular $\mathrm{Ca}^{2+}$ levels within seconds and phosphorylated EGFRs of HTPC/Fs within minutes. Subsequently, decorin blocked EGFR signaling, as evidenced by its action to abolish the mitogenic actions of EGF in HTPC/Fs. It also blocked the mitogenic actions of PDGF, yet the mode of action involves binding of the ligand rather than direct actions at the receptor level.

Are the results obtained in a cell culture system of relevance to the human testis? In the in vivo situation, immunoreactive decorin is found in the interstitial ECM and especially in the ECM of the fibrotically remodeled tubular wall (Adam et al. 2011, 2012). EGFRs are found in peritubular and Leydig cells, and receptors for PDGF are expressed by multiple testicular cells types (Basciani et al. 2010). Thus, in infertile men's testes, substantially higher levels of DCN are found and therefore interference with testicular paracrine signaling must be assumed. This may directly and indirectly contribute to impaired spermatogenesis (Adam et al. 2011, 2012).

It is also noteworthy that the levels of testicular decorin in a non-human primate, the rhesus monkey, are inversely related to the state of fertility. High levels of decorin are 


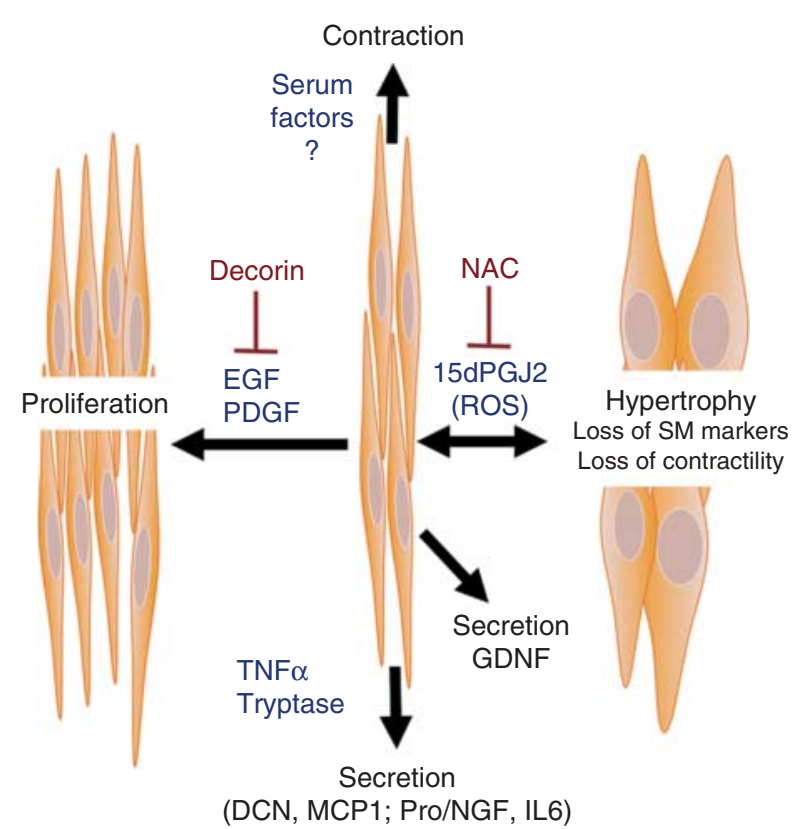

Figure 3 Summary view of factors regulating proliferation, secretion, contraction, and phenotypic plasticity of cultured human peritubular cells. Based on experimental results, EGF and PDFG can stimulate proliferation, actions blocked by decorin. Serum factors induce contraction of HTPCs. Immune cell-derived factors, namely tryptase and/or TNF $\alpha$, induce secretion of several proteins and signaling factors. A PG metabolite (15dPG)2), via ROS, causes cellular hypertrophy and loss of contractility, which can be blocked by an antioxidant (NAC) and is reversible upon removal of the metabolite. GDNF is secreted in a constitutive fashion.

found in immature animals, i.e. the physiological state of 'infertility' and they decrease when sexual maturity approaches. Could decorin be a local regulator of paracrine actions in the testis? Unfortunately, this possibility cannot be readily examined in rodents, because we found that both rats and mice express only very small amounts of decorin in their testes. This may also explain why mutant mice, in which decorin was knocked out, do not have an obvious testicular phenotype (Adam et al. 2011, 2012).

Higher levels of decorin in the ECM of tubular walls of infertile men may be brought about by increased production and/or reduced turnover. The enzyme tryptase is a prototype mast cell product, which acts on target cells via its receptor (PAR2). Macrophages and mast cells, as we found (Schell et al. 2008), are also a source of TNF $\alpha$ in the human testis. Functional PAR2 and TNFR $1 / 2$ are expressed by HTPCs/HTPCFs. Their ligands, tryptase and TNF $\alpha$, stimulated the production and secretion of decorin by HTPCFs, which are derived from men with infertility and testicular fibrosis (Adam et al. 2011, 2012). Provided that higher testicular levels of decorin are related to impaired paracrine signaling and impaired spermatogenesis, immune cells can contribute in this way to male infertility (Fig. 3). Circumstantial evidence for such a link is derived from studies in a mutant mouse (aromatase overexpressing transgenic mouse) ( $\mathrm{Li}$ et al. 2006). These animals become infertile with age. The testicular changes observed after about 3 months of age onward include impaired spermatogenesis, testicular fibroses, abundant macrophages, very high testicular TNF $\alpha$ levels, and very high decorin levels. Thus, male infertility in this mouse is inversely related to high levels of testicular decorin (Adam et al. 2011, 2012). Of course, a causal link remains to be proven.

\section{HTPCs secrete the neurotropic factors (pro)NGF and GDNF}

The physiological importance of the prototype neurotropic factor NGF in the human testis is not known (Seidl et al. 1996). Possible roles have been suggested, including involvement in meiosis in rodents (Perrard et al. 2007, 2009). NGF levels may furthermore be related to the sympathetic innervation of the human testis, which may increase in male infertility (Mayerhofer et al. 1999). NGF may also act on mast cells, e.g. by preventing their apoptosis (Welker et al. 1998, Kanbe et al. 2000, Meineke et al. 2000, Dutta et al. 2011).

In contrast, another neurotropic factor, GDNF, is an established factor and is crucial for the renewal of SSCs in a wide range of species (Oatley \& Brinster 2012). Importantly, the neurotropic factors GDNF and NGF are produced by HTPCs/HTPCFs (Schell et al. 2008, Spinnler et al. 2010, 2011). NGF is normally secreted in low amounts by HTPCs, but TNF $\alpha$ strongly stimulates both expression and secretion levels, as measured by RT-PCR and ELISA in cell culture supernatants respectively. Hence, testicular macrophages and mast cells, which contain TNF $\alpha$ and are present in the tubular wall, could regulate NGF production by peritubular cells via $\mathrm{TNF} \alpha$. Consequently, diverse downstream events (e.g. innervation, number of mast cells, and spermatogenesis) (Schell et al. 2008) may be altered.

In cellular experiments, we found that the mast cell product tryptase also increased the measurable amounts of NGF in cell culture supernatants. The reason for this increase is, however, distinct from the one described above. When we tested a peptide-ligand for PAR2, which lacks the enzymatic activity of tryptase, no stimulatory effect was observed. This puzzling result led to the discovery that the enzyme tryptase cleaves the precursor of NGF, proNGF (Spinnler et al. 2011), which is therefore also secreted by peritubular cells. Tryptase is a specific mast cell product, which does not diffuse far from the site of its secretion. Therefore, mast cells are probably able to modulate the proNGF/NGF levels in their vicinity and thus tubular wall mast cells may influence local NGF- and proNGF-dependent events in the human tubular wall (Fig. 3). Unfortunately, there is no information at all about a role of proNGF in the testis, but its actions are linked to cell death in many organs 
including for instance the human heart, in which it causes microvasculature damage (Siao et al. 2012).

GDNF was found to be a secretory product of both HTPCs and HTPCs, which produce this factor in a constitutive fashion and in similar concentrations, as shown by ELISA measurements (Spinnler et al. 2010). Neither tryptase nor TNF $\alpha$ affected the levels of secreted GDNF. Additional studies (namely RT-PCR of lasermicrodissected areas of human biopsy material) were performed because suitable antibodies for immunohistochemistry were not available. Results obtained imply that GNDF is probably produced by human peritubular cells and by Sertoli cells of the human testis in vivo. The latter cells are accepted testicular producers of this factor in many species. SSCs express a receptor for GDNF, GFR $\alpha-1$, which is readily found in some human basal spermatogonia, which therefore may represent SSCs. Given the anatomical proximity of peritubular cells and SSCs, separated by a basal lamina, paracrine interactions may readily occur. These results therefore have led to the hypothesis that the cells of the tubular wall contribute directly to the SSC niche in the human testis. This idea is currently being explored.

\section{HTPCs, immune factors and reactive oxygen species: phenotype modulation of the contractile state}

In HTPCs, TNF $\alpha$ stimulated the normally low production of pro-inflammatory IL6 and of MCP1 (Schell et al. 2008). MCP1 may be involved in the observed increase in testicular macrophages in infertility patients. Together, with elevated mast cell numbers, more macrophages provide morphological evidence for an inflammatory testicular milieu, which is reported in many cases of male infertility (Schuppe et al. 2008).

A number of soluble factors may be actors in such a microenvironment. They probably include prostaglandins, which are produced by Leydig cells and macrophages in human testes with massively impaired spermatogenesis (Frungieri et al. 2002a, Matzkin et al. 2010). They are also most probably derived from mast cells, albeit only in certain states of partial degenerating of seminiferous tubules. In these 'mixed-atrophy' samples, tryptase-positive mast cells express the prostaglandinsynthesizing enzyme cyclooxygenase 2 (COX2) (Welter et al. 2011). The actions of prostaglandins in the human testis remain to be explored (for review, see Schell et al. $(2007,2010)$ and Kampfer et al. (2012)).

Interestingly, an end-product of non-enzymatic prostaglandin metabolism, 15-deoxy-prostaglandin J2 (15dPGJ2), had a strong influence on cultured HTPCs and HTPCFs (Kampfer et al. 2012). The metabolite induced the generation of reactive oxygen species (ROS), which consequently resulted in a striking phenotype switch of HTPCs (Schell et al. 2010, Welter et al. 2013). The cells became hypertrophic and showed a diminished expression of smooth muscle cell markers (e.g. smooth muscle actin, MYH11, or calponin). This change was associated with a reduced ability to contract upon addition of serum factors, as examined in collagen gel contraction assays. The antioxidant $\mathrm{N}$-acetyl-cysteine (NAC) prevented hypertrophy and loss of smooth muscle markers and of contractility. Furthermore, upon removal of $15 \mathrm{dPGJ} 2$, cells spontaneously reverted to the normal phenotype, indicative of a high intrinsic degree of cellular plasticity.

Is this of relevance for the human testis? Similar phenotypic changes of peritubular cells, namely hypertrophy and reduced smooth muscle marker expression, evolve as common alterations, observed in the testes of infertile men (Schell et al. 2010, Welter et al. 2013). In human testicular samples from infertility patients, 15dPGJ2 can be detected (Kampfer et al. 2012). Circumstantial evidence for increased ROS levels in the tubular wall of infertility patients recently evolved from the comparison between HTPCs and HTPCFs. The latter express higher levels of the $\mathrm{H}_{2} \mathrm{O}_{2}$-metabolizing enzyme catalase and when challenged with $\mathrm{H}_{2} \mathrm{O}_{2}$ respond more effectively. It is thus possible that COX2 expression, prostaglandin formation, and metabolism, which induce the generation of ROS, are interrelated events, forcing smooth muscle-like peritubular cells to adapt and change their phenotype (Fig. 3). If contractility of seminiferous tubules is indeed crucial for sperm transport and fertility, the loss of contractility is an overlooked factor contributing to male infertility.

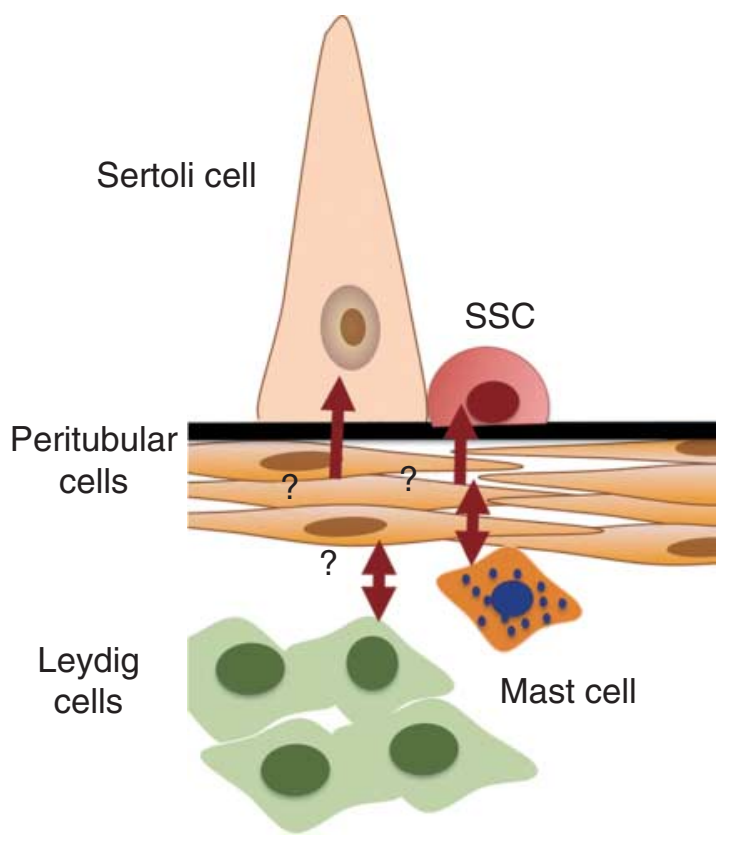

Figure 4 Summary of hypothetic roles of peritubular cells in the human testis. Human peritubular cell may be both sources of and targets for factors involved in the regulation of testicular cells. Leydig cells, Sertoli cells, SSC, and neighboring peritubular cells, as well as immune cells, e.g. mast cells and macrophages, may communicate via secreted proteins or other signaling factors. 


\section{Where do we stand and where should be go?}

The position of the tubular wall within the testis implies that its cells should be able to interact with almost all cell types of the testis, provided that they secrete signaling molecules and possess relevant receptors (Fig. 4). In the case of the human testis, the cellular models of HTPCs and HTCFs and the exploitation of biopsy material are combined approaches, which allow us to decipher such factors and receptors and provide hints of specific roles of peritubular cells in the adult human testis in health and disease. An intriguing result is the unexpected high degree of cellular plasticity, which includes contractile and secretory properties and the insight that peritubular cells are targets of immune-cell-derived factors. The insights may be of translational relevance with regard to treatment of male subfertile or even infertility and with regard to male contraception.

First, if the phenotype of peritubular cells and their functions is subject to regulation by immune cells, is there a safe and effective way to intercept signals from testicular immune cells in subfertility/infertility patients? One approach, the pharmacological inhibition of testicular mast cells, was indeed explored in the past in a limited number of subfertility patients. The reported results were, in general, promising and describe amelioration of subfertility (Matsuki et al. 2000, Azadi et al. 2011, Haidl et al. 2011). Large, controlled, and randomized studies are, however, urgently required in the future to better address this point and to extend it beyond mast cells.

Secondly, is there a safe way to reversibly modulate the contractile and/or secretory phenotype of peritubular cells and would that approach work for human male contraception? Before these points can be clarified, however, much more is to be learned about HTPCs, which appear to be the least explored cells of the human testis.

There are further issues of considerable scientific and clinical interest involving peritubular cells, which were not mentioned in this short paper. They include, for example, the new question whether peritubular cells may have a role in the formation of the testis, as was suggested by the results of a recent rodent study (Nurmio et al. 2012). Answers to an old question, whether the peritubular cell population may contain Leydig cell progenitor or even stem cells, as implied by several studies in rodents, may be provided. Finally, the study of human peritubular cells may help to clarify their potential contribution to germ cell tumor development and progression, which is an emerging topic of clinical relevance (Diez-Torre et al. 2011).

\section{Declaration of interest}

The author declares that there is no conflict of interest that could be perceived as prejudicing the impartiality of the review.

\section{Funding}

Studies mentioned in this review were supported by grants from Deutsche Forschungsgemeinschaft (DFG) to A Mayerhofer, especially MA1080/20-1 and 21-1.

\section{Acknowledgements}

The author thanks former members of the laboratory, namely Marion Adam, Katrin Spinnler, Christoph Schell, Martin Albrecht, Cornelia Kampfer, Silvana Lauf, and Simone Hebele, as well as current members, especially Harald Welter, Astrid Tiefenbacher, Stephanie Gruschka, Daniel Einwang, and Andreas Huber. The author is very grateful to his collaborators Frank-Michael Köhn and Ulrich Schwarzer (Munich, Germany), Matti Poutanen and Leena Strauss (Turku, Finland), Henryk Urbansky (Portland, OR, USA), and Mónica Frungieri and Ricardo Calandra (Buenos Aires, Argentina). He apologizes to all researchers, whose contributions could not be mentioned in this short review. He also thanks Karin Metzrath for assistance in the preparation of the paper.

\section{References}

Adam M, Schwarzer JU, Kohn FM, Strauss L, Poutanen M \& Mayerhofer A 2011 Mast cell tryptase stimulates production of decorin by human testicular peritubular cells: possible role of decorin in male infertility by interfering with growth factor signaling. Human Reproduction 26 2613-2625. (doi:10.1093/humrep/der245)

Adam M, Urbanski HF, Garyfallou VT, Welsch U, Kohn FM, Ullrich Schwarzer J, Strauss L, Poutanen M \& Mayerhofer A 2012 High levels of the extracellular matrix proteoglycan decorin are associated with inhibition of testicular function. International Journal of Andrology 35 550-561. (doi:10.1111/j.1365-2605.2011.01225.x)

Albrecht M 2009 Insights into the nature of human testicular peritubular cells. Annals of Anatomy 191 532-540. (doi:10.1016/j.aanat.2009.08.002)

Albrecht M, Frungieri MB, Gonzalez-Calvar S, Meineke V, Kohn FM \& Mayerhofer A 2005 Evidence for a histaminergic system in the human testis. Fertility and Sterility 83 1060-1063. (doi:10.1016/j.fertnstert. 2004.12.002)

Albrecht M, Ramsch R, Kohn FM, Schwarzer JU \& Mayerhofer A 2006 Isolation and cultivation of human testicular peritubular cells: a new model for the investigation of fibrotic processes in the human testis and male infertility. Journal of Clinical Endocrinology and Metabolism 91 1956-1960. (doi:10.1210/jc.2005-2169)

Alexander MR \& Owens GK 2012 Epigenetic control of smooth muscle cell differentiation and phenotypic switching in vascular development and disease. Annual Review of Physiology 74 13-40. (doi:10.1146/annurevphysiol-012110-142315)

Anthony CT \& Skinner MK 1989 Cytochemical and biochemical characterization of testicular peritubular myoid cells. Biology of Reproduction 40 811-823. (doi:10.1095/biolreprod40.4.811)

Apa DD, Cayan S, Polat A \& Akbay E 2002 Mast cells and fibrosis on testicular biopsies in male infertility. Archives of Andrology 48 337-344. (doi:10.1080/01485010290099183)

Azadi L, Abbasi H, Deemeh MR, Tavalaee M, Arbabian M, Pilevarian AA \& Nasr-Esfahani MH 2011 Zaditen (Ketotifen), as mast cell blocker, improves sperm quality, chromatin integrity and pregnancy rate after varicocelectomy. International Journal of Andrology 34 446-452. (doi:10.1111/j.1365-2605.2010.01112.x)

Basciani S, Mariani S, Spera G \& Gnessi L 2010 Role of plateletderived growth factors in the testis. Endocrine Reviews 31 916-939. (doi:10.1210/er.2010-0004) 
Chemes HE, Gottlieb SE, Pasqualini T, Domenichini E, Rivarola MA \& Bergada C 1985 Response to acute hCG stimulation and steroidogenic potential of Leydig cell fibroblastic precursors in humans. Journal of Andrology 6 102-112. (doi:10.1002/j.1939-4640.1985.tb00824.x)

Chemes H, Cigorraga S, Bergada C, Schteingart H, Rey R \& Pellizzari E 1992 Isolation of human Leydig cell mesenchymal precursors from patients with the androgen insensitivity syndrome: testosterone production and response to human chorionic gonadotropin stimulation in culture. Biology of Reproduction 46 793-801. (doi:10.1095/ biolreprod46.5.793)

Cigorraga SB, Chemes H \& Pellizzari E 1994 Steroidogenic and morphogenic characteristics of human peritubular cells in culture. Biology of Reproduction 51 1193-1205. (doi:10.1095/biolreprod51.6.1193)

Davidoff MS, Breucker H, Holstein AF \& Seidl K 1990 Cellular architecture of the lamina propria of human seminiferous tubules. Cell and Tissue Research 262 253-261. (doi:10.1007/BF00309880)

Diez-Torre A, Silvan U, Moreno P, Gumucio J \& Arechaga J 2011 Peritubular myoid cell-derived factors and its potential role in the progression of testicular germ cell tumours. International Journal of Andrology 34 e252-e264 (discussion e264-255). (doi:10.1111/j.13652605.2011.01168.x)

Du S, Powell J, Hii A \& Weidner N 2012 Myoid gonadal stromal tumor: a distinct testicular tumor with peritubular myoid cell differentiation. Human Pathology 43 144-149. (doi:10.1016/j.humpath.2011.04.017)

Duchesne E, Tremblay MH \& Cote CH 2011 Mast cell tryptase stimulates myoblast proliferation; a mechanism relying on protease-activated receptor-2 and cyclooxygenase-2. BMC Musculoskeletal Disorders 12 235. (doi:10.1186/1471-2474-12-235)

Dutta P, Koch A, Breyer B, Schneider H, Dittrich-Breiholz O, Kracht M \& Tamura T 2011 Identification of novel target genes of nerve growth factor (NGF) in human mastocytoma cell line (HMC-1 (V560G c-Kit)) by transcriptome analysis. BMC Genomics 12 196. (doi:10.1186/14712164-12-196)

Frungieri MB, Weidinger S, Meineke V, Kohn FM \& Mayerhofer A 2002a Proliferative action of mast-cell tryptase is mediated by PAR2, COX2, prostaglandins, and PPARgamma: possible relevance to human fibrotic disorders. PNAS 99 15072-15077. (doi:10.1073/pnas.232422999)

Frungieri MB, Calandra RS, Lustig L, Meineke V, Kohn FM, Vogt HJ \& Mayerhofer A 2002b Number, distribution pattern, and identification of macrophages in the testes of infertile men. Fertility and Sterility 78 298-306. (doi:10.1016/S0015-0282(02)03206-5)

Haider SG, Talati J \& Servos G 1999 Ultrastructure of peritubular tissue in association with tubular hyalinization in human testis. Tissue \& Cell 31 90-98. (doi:10.1054/tice.1999.0005)

Haidl G, Duan YG, Chen SJ, Kohn FM, Schuppe HC \& Allam JP 2011 The role of mast cells in male infertility. Expert Review of Clinical Immunology 7 627-634. (doi:10.1586/eci.11.57)

Hargrove JL, MacIndoe JH \& Ellis LC 1977 Testicular contractile cells and sperm transport. Fertility and Sterility 28 1146-1157.

Hashimoto J, Nagai T, Takaba H, Yamamoto M \& Miyake K 1988 Increased mast cells in the limiting membrane of seminiferous tubules in testes of patients with idiopathic infertility. Urologia Internationalis 43 129-132. (doi:10.1159/000281324)

Howl J, Rudge SA, Lavis RA, Davies AR, Parslow RA, Hughes PJ, Kirk CJ, Michell RH \& Wheatley M 1995 Rat testicular myoid cells express vasopressin receptors: receptor structure, signal transduction, and developmental regulation. Endocrinology 136 2206-2213. (doi:10.1210/en.136.5.2206)

Hussein MR, Abou-Deif ES, Bedaiwy MA, Said TM, Mustafa MG, Nada E, Ezat A \& Agarwal A 2005 Phenotypic characterization of the immune and mast cell infiltrates in the human testis shows normal and abnormal spermatogenesis. Fertility and Sterility 83 1447-1453. (doi:10.1016/j. fertnstert.2004.11.062)

Kampfer C, Spillner S, Spinnler K, Schwarzer JU, Terradas C, Ponzio R, Puigdomenech E, Levalle O, Kohn FM, Matzkin ME et al. 2012 Evidence for an adaptation in ROS scavenging systems in human testicular peritubular cells from infertility patients. International Journal of Andrology 35 793-801. (doi:10.1111/j.1365-2605.2012.01281.x)

Kanbe N, Kurosawa M, Miyachi Y, Kanbe M, Saitoh H \& Matsuda H 2000 Nerve growth factor prevents apoptosis of cord blood-derived human cultured mast cells synergistically with stem cell factor. Clinical and Experimental Allergy 30 1113-1120. (doi:10.1046/j.1365-2222.2000. 00866.x)

Levi-Schaffer F \& Piliponsky AM 2003 Tryptase, a novel link between allergic inflammation and fibrosis. Trends in Immunology 24 158-161. (doi:10.1016/S1471-4906(03)00058-9)

Li X, Strauss L, Kaatrasalo A, Mayerhofer A, Huhtaniemi I, Santti R, Makela S \& Poutanen M 2006 Transgenic mice expressing p450 aromatase as a model for male infertility associated with chronic inflammation in the testis. Endocrinology 147 1271-1277. (doi:10.1210/ en.2005-0654)

Losinno AD, Morales A, Fernandez D \& Lopez LA 2012 Peritubular myoid cells from rat seminiferous tubules contain actin and myosin filaments distributed in two independent layers. Biology of Reproduction 150 151-158. (doi:10.1095/biolreprod.111.095158)

Maekawa M, Kamimura K \& Nagano T 1996 Peritubular myoid cells in the testis: their structure and function. Archives of Histology and Cytology $\mathbf{5 9}$ 1-13. (doi:10.1679/aohc.59.1)

Matsuki S, Sasagawa I, Suzuki Y, Yazawa H, Tateno T, Hashimoto T, Nakada T, Saito H \& Hiroi M 2000 The use of ebastine, a mast cell blocker, for treatment of oligozoospermia. Archives of Andrology $\mathbf{4 4}$ 129-132. (doi:10.1080/014850100262290)

Matzkin ME, Mayerhofer A, Rossi SP, Gonzalez B, Gonzalez CR, Gonzalez-Calvar SI, Terradas C, Ponzio R, Puigdomenech E, Levalle $\mathbf{O}$ et al. 2010 Cyclooxygenase-2 in testes of infertile men: evidence for the induction of prostaglandin synthesis by interleukin-1 $\beta$. Fertility and Sterility 94 1933-1936. (doi:10.1016/j.fertnstert.2010.01.039)

Mayerhofer A, Frungieri MB, Fritz S, Bulling A, Jessberger B \& Vogt HJ 1999 Evidence for catecholaminergic, neuronlike cells in the adult human testis: changes associated with testicular pathologies. Journal of Andrology 20 341-347. (doi:10.1002/j.1939-4640.1999.tb02527.x)

Meineke V, Frungieri MB, Jessberger B, Vogt H \& Mayerhofer A 2000 Human testicular mast cells contain tryptase: increased mast cell number and altered distribution in the testes of infertile men. Fertility and Sterility 74 239-244. (doi:10.1016/S0015-0282(00)00626-9)

Merline R, Moreth K, Beckmann J, Nastase MV, Zeng-Brouwers J, Tralhao JG, Lemarchand P, Pfeilschifter J, Schaefer RM, lozzo RV et al. 2011 Signaling by the matrix proteoglycan decorin controls inflammation and cancer through PDCD4 and microRNA-21. Science Signaling 4 ra75. (doi:10.1126/scisignal.2001868)

Miyake K, Yamamoto M, Narita H, Hashimoto J \& Mitsuya H 1986 Evidence for contractility of the human seminiferous tubule confirmed by its response to noradrenaline and acetylcholine. Fertility and Sterility $\mathbf{4 6}$ 734-737.

Nagai T, Takaba H, Miyake K, Hirabayashi Y \& Yamada K 1992 Testicular mast cell heterogeneity in idiopathic male infertility. Fertility and Sterility 57 1331-1336.

Nurmio M, Kallio J, Adam M, Mayerhofer A, Toppari J \& Jahnukainen K 2012 Peritubular myoid cells have a role in postnatal testicular growth. Spermatogenesis 2 79-87. (doi:10.4161/spmg.20067)

Oatley JM \& Brinster RL 2012 The germline stem cell niche unit in mammalian testes. Physiological Reviews 92 577-595. (doi:10.1152/ physrev.00025.2011)

Perrard MH, Vigier M, Damestoy A, Chapat C, Silandre D, Rudkin BB \& Durand P $2007 \beta$-Nerve growth factor participates in an auto/paracrine pathway of regulation of the meiotic differentiation of rat spermatocytes. Journal of Cellular Physiology 210 51-62. (doi:10.1002/jcp.20805)

Perrard MH, Chassaing E, Montillet G, Sabido O \& Durand P 2009 Cytostatic factor proteins are present in male meiotic cells and $\beta$-nerve growth factor increases mos levels in rat late spermatocytes. PLOS ONE 4 e7237. (doi:10.1371/journal.pone.0007237)

Roaiah MM, Khatab H \& Mostafa T 2007 Mast cells in testicular biopsies of azoospermic men. Andrologia 39 185-189. (doi:10.1111/j.1439-0272. 2007.00793.x)

Romano F, Tripiciano A, Muciaccia B, De Cesaris P, Ziparo E, Palombi F \& Filippini A 2005 The contractile phenotype of peritubular smooth muscle cells is locally controlled: possible implications in male fertility. Contraception 72 294-297. (doi:10.1016/j.contraception.2005.03.009)

Romano F, Chiarenza C, Palombi F, Filippini A, Padula F, Ziparo E \& De Cesaris P 2006 Platelet-derived growth factor-BB-induced hypertrophy of 
peritubular smooth muscle cells is mediated by activation of p38 MAPkinase and of Rho-kinase. Journal of Cellular Physiology 207 123-131. (doi:10.1002/jcp.20554)

Romano F, Gambara G, De Cesaris P, Ziparo E, Palombi F \& Filippini A 2007 Endothelin induces functional hypertrophy of peritubular smooth muscle cells. Journal of Cellular Physiology 212 264-273. (doi:10.1002/ jcp.21028)

Schell C, Frungieri MB, Albrecht M, Gonzalez-Calvar SI, Kohn FM, Calandra RS \& Mayerhofer A 2007 A prostaglandin D2 system in the human testis. Fertility and Sterility $\mathbf{8 8}$ 233-236. (doi:10.1016/j.fertnstert. 2006.11.100)

Schell C, Albrecht M, Mayer C, Schwarzer JU, Frungieri MB \& Mayerhofer A 2008 Exploring human testicular peritubular cells: identification of secretory products and regulation by tumor necrosis factor- $\alpha$. Endocrinology 149 1678-1686. (doi:10.1210/en.2007-1064)

Schell C, Albrecht M, Spillner S, Mayer C, Kunz L, Kohn FM, Schwarzer U \& Mayerhofer A 2010 15-Deoxy-delta 12-14-prostaglandin-J2 induces hypertrophy and loss of contractility in human testicular peritubular cells: implications for human male fertility. Endocrinology 151 1257-1268. (doi:10.1210/en.2009-1325)

Schlatt S, Weinbauer GF, Arslan M \& Nieschlag E 1993 Appearance of $\alpha$-smooth muscle actin in peritubular cells of monkey testes is induced by androgens, modulated by follicle-stimulating hormone, and maintained after hormonal withdrawal. Journal of Andrology 14 340-350. (doi:10. 1002/j.1939-4640.1993.tb00397.x)

Schuppe HC, Meinhardt A, Allam JP, Bergmann M, Weidner W \& Haidl G 2008 Chronic orchitis: a neglected cause of male infertility? Andrologia 40 84-91. (doi:10.1111/j.1439-0272.2008.00837.x)

Seidl K, Buchberger A \& Erck C 1996 Expression of nerve growth factor and neurotrophin receptors in testicular cells suggest novel roles for neurotrophins outside the nervous system. Reproduction, Fertility, and Development 8 1075-1087. (doi:10.1071/RD9961075)

Siao CJ, Lorentz CU, Kermani P, Marinic T, Carter J, McGrath K, Padow VA, Mark W, Falcone DJ, Cohen-Gould L et al. 2012 ProNGF, a cytokine induced after myocardial infarction in humans, targets pericytes to promote microvascular damage and activation. Journal of Experimental Medicine 209 2291-2305. (doi:10.1084/jem.20111749)

Skinner MK \& Fritz IB 1985 Testicular peritubular cells secrete a protein under androgen control that modulates Sertoli cell functions. PNAS $\mathbf{8 2}$ 114-118. (doi:10.1073/pnas.82.1.114)

Spiess AN, Feig C, Schulze W, Chalmel F, Cappallo-Obermann H, Primig M \& Kirchhoff C 2007 Cross-platform gene expression signature of human spermatogenic failure reveals inflammatory-like response. Human Reproduction 22 2936-2946. (doi:10.1093/humrep/dem292)

Spinnler K, Kohn FM, Schwarzer U \& Mayerhofer A 2010 Glial cell line-derived neurotrophic factor is constitutively produced by human testicular peritubular cells and may contribute to the spermatogonial stem cell niche in man. Human Reproduction 25 2181-2187. (doi:10.1093/humrep/deq170)
Spinnler K, Frohlich T, Arnold GJ, Kunz L \& Mayerhofer A 2011 Human tryptase cleaves pro-nerve growth factor (pro-NGF): hints of local, mast cell-dependent regulation of NGF/pro-NGF action. Journal of Biological Chemistry 286 31707-31713. (doi:10.1074/jbc.M111.233486)

Tripiciano A, Filippini A, Ballarini F \& Palombi F 1998 Contractile response of peritubular myoid cells to prostaglandin F2 $\alpha$. Molecular and Cellular Endocrinology 138 143-150. (doi:10.1016/S0303-7207(98)00010-0)

Tung PS \& Fritz IB 1990 Characterization of rat testicular peritubular myoid cells in culture: $\boldsymbol{\alpha}$-smooth muscle isoactin is a specific differentiation marker. Biology of Reproduction 42 351-365. (doi:10.1095/biol reprod42.2.351)

Ungefroren H, Ergun S, Krull NB \& Holstein AF 1995 Expression of the small proteoglycans biglycan and decorin in the adult human testis. Biology of Reproduction 52 1095-1105. (doi:10.1095/biolreprod52.5.1095)

Verhoeven G, Hoeben E \& De Gendt K 2000 Peritubular cell-Sertoli cell interactions: factors involved in PmodS activity. Andrologia 32 42-45. (doi:10.1111/j.1439-0272.2000.tb02863.x)

Welker P, Grabbe J, Grutzkau A \& Henz BM 1998 Effects of nerve growth factor (NGF) and other fibroblast-derived growth factors on immature human mast cells (HMC-1). Immunology 94 310-317.

Welsh M, Saunders PT, Atanassova N, Sharpe RM \& Smith LB 2009 Androgen action via testicular peritubular myoid cells is essential for male fertility. FASEB Journal 23 4218-4230. (doi:10.1096/fj.09-138347)

Welsh M, Moffat L, Belling K, de Franca LR, Segatelli TM, Saunders PT, Sharpe RM \& Smith LB 2012 Androgen receptor signalling in peritubular myoid cells is essential for normal differentiation and function of adult Leydig cells. International Journal of Andrology 35 25-40. (doi:10.1111/ j.1365-2605.2011.01150.x)

Welter H, Kohn FM \& Mayerhofer A 2011 Mast cells in human testicular biopsies from patients with mixed atrophy: increased numbers, heterogeneity, and expression of cyclooxygenase 2 and prostaglandin D2 synthase. Fertility and Sterility 96 309-313. (doi:10.1016/j.fertnstert. 2011.05.035)

Welter H, Kampfer C, Lauf S, Feil R, Schwarzer JU, Kohn FM \& Mayerhofer A 2013 Partial loss of contractile marker proteins in human testicular peritubular cells in infertility patients. Andrology 1 318-324. (doi:10.1111/j.2047-2927.2012.00030.x)

Yamamoto M, Nagai T, Takaba H, Hashimoto J \& Miyake K 1989 In-vitro contractility of human seminiferous tubules in response to testosterone, dihydrotestosterone and estradiol. Urological Research 17 265-268. (doi:10.1007/BF00262608)

Zhang C, Yeh S, Chen YT, Wu CC, Chuang KH, Lin HY, Wang RS, Chang YJ, Mendis-Handagama C, Hu L et al. 2006 Oligozoospermia with normal fertility in male mice lacking the androgen receptor in testis peritubular myoid cells. PNAS 103 17718-17723. (doi:10.1073/pnas.0608556103)

Received 1 December 2012

First decision 29 January 2013

Accepted 21 February 2013 